\title{
POLIQUIMIOTERAPIA DA HANSENIASE: A IMPLANTAÇÃO NA UNIDADE DE SAÚDE DE SÃO CARLOS - SP*
}

\author{
Eliana C. Petoilho** \\ Maria Cristina M. de Lima*** \\ Elisete Silva Pedrazzani"****
}

\begin{abstract}
RESUMO: No presente estudo caracteriza-se a população de doentes sob poliquimioterapia em hanseníase, no Ambulatório Regional de Especialidades, assim como analisa-se as ações desenvolvidas e dificuldades encontradas na implantação do novo esquema terapéutico, tanto do ponto de vista do paciente, quanto dos profissionais que atuam na área. Verificou-se que $68,5 \%$ dos pacientes acreditam no tratamento e $89,5 \%$ relataram que sentem-se mais seguros com esse novo esquema terapêutico; dos entrevistados, $44,6 \%$ alegaram dificuldades com o transporte e problemas financeiros para a realização do mesmo. Quanto aos profissionais, $88,4 \%$ afimaram que a poliquimioterapia contribuiu para promover um melhor controle de doenças e a maior dificuldade encontrada concentra-se nos problemas organizacionais $(50,0 \%)$. Dos entrevistados, $83,3 \%$ confiam no tratamento e $33,4 \%$ ainda não acreditam na cura da doença.
\end{abstract}

ABSTRACT: In the present study the target population has been leprosy patients submitted to multidrug therapy at a regional health specialities out patient service. The actions and difficulties that ocurred during the experience of this new therapeutic scheme, have been analysed from the patients and also from the various professionals point of view. It has been verified that $68,5 \%$ of the patients believed in the treatment, and $89,5 \%$ reported to feel more secure with this new therapeutic scheme, $44,6 \%$ of the interviewed patients quoted financial and transportation problems to follow treatment. Among the professionals, $88,4 \%$ assert that multidrug therapy contributed to promote a better control of disease and their greatest difficulty was concentrated in organizational problems (50,0\%); $83,3 \%$ believed in the treatment , and $33,4 \%$ didn't believe in the cure of the disease.

\section{INTRODUÇÃO}

A hanseniase é uma doença transmissivel, de evolução lenta(2). O agente causador é um bacilo denominado Mycobacterium leprae pertencente à familia das microbactérias. $O M$. leprae é um parasita intracelular obrigatório que apresenta afinidades por células cutâneas e por células dos nervos periféricos(9). Este bacilo é encontrado apenas no homem; isto quer dizer que uma pessoa com hanseniase é a única fonte de infecção que se conhece(7).
A disseminação da hanseniase, de uma pessoa contaminada para uma pessoa não contaminada é possivel, mas mesmo assim é uma doença de baixa contagiosidade( $(7)$, pois o grau de infectividade e patogenicidade do bacilo é baixo. A hanseniase é uma doença de transmissão respiratória, mas até o momento não existem provas conclusivas de que seja a única fonte transmissão. Há estudos sendo realizados que evidenciam a transmissão do bacilo por via cutânea(9). Para efeitos operacionais, os doentes de hanseníase são classificados da seguinte

\footnotetext{
- Trabalho realizado em parte com o auxilio do CNPq.

** Enfermeira em estágio no exterior, ex-aluna do curso de graduaçáo em Enfermagem da UFSCar.

*** Enfermeira do Hospital Sarah Kubitschek.

**** Profe. Dra. do Departamento de Enfermagem da Universidade Federal de Sáo Carlos.
} 
forma: Paucibacilares, que englobam as formas clínicas $\mathrm{T}, \mathrm{I}+\mathrm{e}$ os multibacilares que incluem as formas V, D e I-, o que contribui para a verificação das estratégias adotadas no programa de eliminação e controle da doença.

A magnitude e transcendência na qual está inserida a hanseniase caracterizam-na como um problema de saúde pública nos países em desenvolvimento, onde aproximadamente $1,6 \mathrm{bi}$ Ihões de pessoas vivem em áreas consideradas endêmicas. LOMBARDI, referindo-se à transcendência da hanseniase salienta para

o fato de que um terço dos casos diagnosticados em fases avançadas e/ou não adequadamente tratadas em incapacidade fisicas progressivas $e$ permanentes afetando principalmente a face e os membros, faz com que a hanseniase tenha sua importáncia relativa avaliada, em função não só do número de casos, mas também pelo sofrimento humano, discriminação social e prejuizos económicos que vem sempre associados com a doença(9).

É importante considerar que as condições gerais de vida de uma população influem acentuadamente no quadro epidemiológico da hanseniase ${ }^{(10)}$. Como exemplo, temos a observação secular da tendência da endemia no período compreendido entre a metade do século passado e a segunda década deste século na Noruega, quando profundas alterações do status sócio-econômico e dos padrões de higiene, provocados pela revolução industrial, levaram praticamente ao desaparecimento da hanseníase do país( ${ }^{(9)}$.

Observa-se portanto uma maior frequência desta doença em classes menos favorecidas, carentes de alimentação e conduta higiênica(6). A hanseníase é uma doença endêmica em quase todos países da América(13). Contribuem para a persistência da endemia, em muitas áreas do continente, as baixas condições sócioeconômicas da população, situação para qual não se oferecem soluções a curto prazo(14).

A Organização Mundial de Saúde (OMS), analisando o problema da prevalência da doença estabeleceu os seguintes parâmetros: até 0,2 casos por mil habitantes - corresponde ao coeficiente de baixa prevalência; 0,2 a 1,0 caso por mil habitantes - corresponde ao coeficiente de média prevalência; quando atinge mais que 1,0 caso por mil habitantes, considera-se um coeficiente de alta prevalência. A hanseniase é responsável por 5.069.283 pacientes registrados no mundo, no ano de 1988, o que corresponde a um coeficiente de 1,06 casos por mil habitantes, portanto de alta prevalência(9).

Em análise retrospectiva de uma série temporal das taxas de detecção da hanseniase nos países da região, as mesmas indicaram que em vários deles a endemia parece estar declinando ou permanece estacionária, com exceção do Brasil, onde a situação é inversa, e a linha da tendência para os últimos treze anos analisados (1970-1983) é ascendente ${ }^{(14)}$. Nas Américas 0 total do número de casos em registro ativo é de 335.232, sendo que só no Brasil temos 256.979 casos. Isto significa que mais da metade dos casos de hanseniase nas Américas está localizado no Brasil(9).

Segundo as Secretarias Estaduais de Saúde/Divisão Nacional de Dermatologia Sanitária Ministério da Saúde, a distribuição por macroregiőes em número de caso novos registrados no Brasil no ano de 1988, apresentou o seguinte quadro:

$\begin{array}{ll}\text { Norte } & 6.877 \text { casos } \\ \text { Centro Oeste } & 4.875 \text { casos } \\ \text { Nordeste } & 4.556 \text { casos } \\ \text { Sul } & 1.855 \text { casos } \\ \text { Sudeste } & 8.415 \text { casos }\end{array}$

Isto soma um total de 26.578 casos novos, equivalentes a uma taxa de detecção de 18,4 por cem mil habitantes ${ }^{(9)}$.

O maior número absoluto de casos novos no Brasil foi encontrado na região Sudeste, havendo uma maior ocorrência dos mesmos no Estado de São Paulo(3).

Análises epidemiológicas demostraram que nos últimos anos há uma ascensão da endemia no Brasil, estimando-se em torno de $3 \%$ acima do crescimento populacional, isto é, há um aumento do número real dos casos. Ao mesmo tempo, verifica-se um aumento significativo na detecção da forma tuberculóide quando comparada às outras formas, assim como um aumento de diagnósticos em faixas etárias jovens, abaixo de quinze anos(17).

O estado de São Paulo é dividido em cinco 
Coordenações de Regiões de Saúde (CRS). A região de São Carlos que pertence à CRS III apresentou um coeficiente de prevalência de 1,28 por mil habitantes no ano de 1990 . O coeficiente de prevalência em São Carlos, sede do Escritóriọ Regional de Saúde de São Carlos (ERSA-53), é de 1,2 por mil habitantes neste mesmo ano.

Durante muito tempo não houve tratamento eficiente para a moléstia. Nos leprosários, os pacientes eram tratados com injeção de Chaulmugra, uma semente trazida da Índia, porém não se obtiveram resultados positivos, aparecendo cada vez mais doentes(6). Nesses leprosários, o doente sentia solidão, desânimo, melancolia, atenuados pela visita dos familiares, pelo médico, atendentes e novas amizades. A adaptação à nova vida era lenta e ocorria após meses ou anos. Após alta hospitalar, havia dificuldades de reintegração na comunidade, no trabalho e a marginalização social devido à institucionalização era freqüente.

O primeiro avanço contra a doença foi a partir de 1941 com o advento das Sulfonas e de outras drogas(1). Nesta época, o isolamento deixou de ser adotado em vários lugares do mundo(8). Reduziram-se as despesas com as investigações e maiores verbas puderam ser destinadas a partes essenciais como: atividade de controle, diagnóstico e tratamento precoce, atenuando portanto o trauma psicológico e aspectos sociais para o doente(1).

Entretanto, após a metade da década de 60, são descritos os primeiros casos de resistência sulfônica, caindo o entusiasmo pela dapsona (DDS). Na década de setenta duas drogas foram incorporadas à terapia anti-hansênica: a rifampicina (RFM), que tem ação bactericida e a Clofazimina (CFZ) com ação bacteriostática e anti-inflamatória(11).

É importante ressaltar que, até então, uma parcela significativa de pacientes em tratamento, o abandonavam ainda numa fase contagiosa da doença, trazendo riscos à população e a si próprio(18).

Alguns fatores que levaram ao abandono do tratamento são:
a. longo período de tratamento;
b. atendimento deficiente ao paciente;

c. discriminação social.

Em 1981, em vista do problema da resistência aos medicamentos e a necessidade de introduzir esquemas terapêuticos eficazes e viáveis de duração definida, o grupo de estudos da Organização Mundial de Saúde sobre quimioterapia da hanseníase visando um maior controle da doença recomenda novos regimes terapêuticos, destacando-se 0 da Poliquimioterapia (PQT) ${ }^{(12) .}$

A poliquimioterapia, estratégia atual de controle para a hanseníase, foi adotada pelo Ministério da Saúde, no Brasil, a partir de 1986. Constitui-se na adoção de um esquema terapêutico tríplice, cuja eficácia possibilita a redução do tempo de tratamento para a obtenção da cura e numa nova filosofia assistencial. Exige, para tanto, uma organização dos serviços diferente da usual com o tratamento tradicional. Esta organização compreende a instituição adequada da terapêutica, a realização oportuna de ações de prevenção de incapacidades, educação para a saúde do individuo, família e comunidade, exigindo, ainda, a introdução de outros agentes no processo de trabalho( $(8)$.

As recentes mudanças administrativas e organizacionais do sistema de saúde ocorridas a nível federal, implicam na necessária e urgente revisão das estratégias, metas e propostas do atual Programa de Controle da Hanseniase $(\mathrm{PCH})$ a nível do estado de São Paulo. Dessa forma foram elaboradas estratégias no sentido de agilizar os procedimentos para a implantação do novo esquema terapêutico, considerando os diferentes momentos por que passavam as unidades de saúde do estado.

A poliquimioterapia foi introduzida no estado de São Paulo, a partir de 1988, através de projetos isolados localizados em Unidades básicas de Saúde, conforme recomendações do Ministério da Saúde(5).

No final de 1989, o Ministério da Saúde reviu suas estratégias para a implantação deste esquema terapêutico e, por meio da portaria $n^{0} 1$ de 07/11/89 da Divisão Nacional de Dermatologia Sanitária a PQT passou a ser preconizada como esquema nacional a partir de 1991.

Em 07 de agosto de 1992, por meio da Portaria $n^{\circ} 864 / G M$, foram expedidas novas instruções normativas visando o desenvolvimento 
de ações destinadas à orientação e acompanhamento da execução do programa de controle e eliminação da hanseniase em todo território nacional(4).

As atividades de controle e eliminação dessa doença têm como objetivos:

a. a redução da morbidade expressa pela incidência e prevalência da doença;

b. a redução dos danos causados pela doença, expressos pela gravidade das incapacidades físicas e psico-sociais.

Visando a consecução dos objetivos, o controle e eliminação da hanseniase será orientado para as seguintes atividades:

a. detecção de casos através do atendimento de demanda passiva, com prioridade aos sintomáticos dermatoneurológicos, e através de busca ativa, com ênfase na vigilância de contatos;

b. tratamento integral dos casos, em regime eminentemente ambulatorial, compreendendo:

1. Quimioterapia específica, visando a cura e a eliminação de infecção.

Esquema padrão:

Paucibacilar: $600 \mathrm{mg}$ de Rifampicina uma vez por mês supervisionada e $100 \mathrm{mg}$ de Dapsona uma vez ao dia auto-administrada.

Multibacilar: $600 \mathrm{mg}$ de Rifampicina uma vez por mês supervisionada, $100 \mathrm{mg}$ de Dapsona uma vez ao dia auto-administrada e $300 \mathrm{mg}$ de Clofazimina uma vez por mês supervisionada mais $100 \mathrm{mg}$ em dias alternados ou $50 \mathrm{mg}$ diários auto-administrada.

2. Tratamento das intercorrências e/ou complica-ções, inclusive em regime hospitalar, quando houver indicação médica;

3. Reabilitação física, readaptação psico-social, abrangendo: recuperação de incapacidades físicas, readaptaçảo profissional e reinserção social do doente e seus familiares.

Outros componentes do programa são: o desenvolvimento de recursos humanos, educaçåo em saúde, incentivo à pesquisa e atividades administrativas (4).

A cidade de São Carlos, encontra-se hoje com o projeto de implantação da poliquimioterapia em fase adiantada, sendo que toda a equipe que atua na área recebeu treinamento adequado de forma a dar suporte necessário a essa etapa.

Considerando a implantação desse novo regime terapêutico, na unidade de saúde de São Carlos, propomos e desenvolvimento desse projeto, de acordo com os objetivos expressos a seguir.

\section{OBJETIVOS}

- Caracterizar os casos em tratamento poliquimioterápico no Ambulatório Regional de Especialidades (ARE) de São Carlos.

- Identificar as ações que estão sendo desenvolvidas nessa unidade de saúde, no que se refere ao acompanhamento do doente em PQT.

- Cotejar as ações desenvolvidas no ARE e as preconizadas pelo Programa de Controle e Eliminação da Hanseniase.

- Identificar as dificuldades que estão sendo encontradas na implantação do novo esquema terapêutico, tanto do ponto de vista do paciente quanto dos profissionais da área.

- Propor medidas que subsidiem a operacionalizaçåo do programa.

- Atuar junto ao programa de forma a contribuir na resoluçåo dos problemas identificados.

\section{METODOLOGIA}

\subsection{Local de estudo}

O estudo foi realizado no ARE, na cidade de São Carlos, sede do Escritório Regional de Saúde de São Carlos (ERSA-53), distante 230 km de São Paulo, situada na região central do estado, com uma população de 158.139 habitantes (IBGE-1992).

\subsection{População}

A populaçåo estudada foi constituida por:

- Todos os casós de hanseníase em tratamento poliquimioterápico no ARE, no período de setembro a novembro de 1992.

- Os profissionais que atuam diretamente na área, como por exemplo o médico, enfermei- 
ra, fisioterapeuta, auxiliar de enfermagem e outros.

\subsection{Instrumento} se de:

O instrumento de coleta de dados constitui-

- formulário para registro de dados que foram obtidos através do prontuário e entrevista com o paciente;

- formulário para registro dos dados que foram obtidos através da entrevista com os profissionais que atuam na área.

\subsection{Procedimento}

Quando do planejamento do projeto, entrouse em contato com a Diretoria Técnica do ARE, médicos consultantes na área e enfermeiras da unidade, que manifestaram interesse e apoio no desenvolvimento do mesmo.

Numa segunda etapa realizou-se:

- Observação ativa, visando um reconhecimento e integração maior com a área, com a devida identificação dos casos atendidos na unidade.

- Categorização dos casos de acordo com os critérios de tratamento adotados na norma técnica específica para os casos multi e paucibacilares; posteriormente, registrou-se no formulário os dados de cada paciente, obtidos diretamente dos prontuários e da entrevista.

- Entrevistas com os profissionais que atuam diretamente na área, e o devido registro no instrumento destinado a essa finalidade.

\section{RESULTADOS E DISCUSSÃO}

A unidade de dermatologia do Ambulatório Regional de Especialidades, contava em novembro de 1992, com 130 pacientes inscritos no Programa de Controle e Eliminação da Hanseníase, sendo que destes, 44 estavam sob tratamento poliquimioterápico (esquema padrão), onde 3 pacientes eram pauci 41 multibacilares. Os 86 restantes estavam recebendo o tratamento monoterápico ou "DNDS".

A população estudada reuniu um total de 38 pacientes, portanto teve-se a perda de 6 deles em função de: a. não comparecimento dos mesmos embora tivessem recebido aerograma, comunicando a necessidade da presença ao serviço;

b. endereço ignorado;

c. falta de disponibilidade de horário para a realização da entrevista, por parte do paciente.

Também fizeram parte da amostra 6 profissionais envolvidos diretamente com as ações do programa. Esta população constou de 1 enfermeira, 1 auxiliar de enfermagem, 2 médicos, 1 fisioterapeuta e 1 terapeuta ocupacional.

\subsection{Análise dos dados relacionados aos pacientes}

Os dados levantados apontam que nessa amostra, há um predomínio do sexo masculino (24) sobre o feminino (14). Em relação à idàde todos são maiores de 15 anos conforme os dados apresentados na tabela 1.

Tabela 1: Distribuição dos casos de hanseniase em polioquimioterapia segundo a faixa etária e forma clínica - São Carlos, 1992.

\begin{tabular}{|c|c|c|c|c|c|c|}
\hline \multirow{2}{*}{$\begin{array}{l}\text { Faixa } \\
\text { Etária }\end{array}$} & \multicolumn{4}{|c|}{ Forma Clínica } & \multirow[t]{2}{*}{$\mathrm{N}^{0}$} & \multirow[t]{2}{*}{$\%$} \\
\hline & V & D & $T$ & It & & \\
\hline $15-30$ & 3 & 1 & 1 & 1 & 6 & 15,8 \\
\hline $30-40$ & 7 & 3 & - & - & 10 & 26,3 \\
\hline $40-50$ & 1 & 2 & - & - & 3 & 79 \\
\hline $50-60$ & 6 & 2 & - & - & 8 & 21,0 \\
\hline$>60$ & 7 & 4 & - & - & 11 & 29,0 \\
\hline TOTAL & 24 & 12 & 1 & 1 & 38 & 100,0 \\
\hline
\end{tabular}

Observou-se maior concentração dos pacientes nos polos D (12) e V (24), o que representam $94,7 \%$ da amostra estudada. Quando comparamos os dados encontrados com o número de caso em registro ativo, fomecidos pela Divisão Técnica de DST/AIDS e Hanseníase do Estado de São Paulo em 1991(17), observamos uma tendência semelhante quanto ao predomínio de doentes de maior faixa etária nos polos mais avançados da doença. Diferentemente do que tem sido observado, quando são analisados os números de casos novos distribuídos por faixa etária segundo a forma, onde se destaca o número de paucibacilares maiores de 15 anos sob o número de multibacilares na mesma faixa etária. 
Tabela 2: Distribuição das respostas dos pacientes segundo o tempo de diagnóstico - São Carlos, 1992.

\begin{tabular}{c|c|c}
\hline Tempo (anos) & Número & $\%$ \\
\hline $0-2$ & 10 & 26,3 \\
\hline $2-4$ & 10 & 26,3 \\
\hline$>4$ & 18 & 47,4 \\
\hline TOTAL & 38 & 100,0 \\
\hline
\end{tabular}

De acordo com a tabela $2,47,4 \%$ dos pacientes foram diagnosticados há mais de 4 anos enquanto os demais o foram entre 0 e 4 anos.

Dos pacientes que iniciaram a PQT, 11 (29\%) eram virgens de tratamento, os demais 27 (71\%) já haviam recebido algum outro tipo de medicação, portanto atualmente tem-se 36 pacientes recebendo drogas RFM, CFZ e DDS, enquadrados no tratamento para multibacilar enquanto apenas 2 com RFM e DDS, ou seja paucibacilar.

Quanto ao estado reacional, $39,5 \%$ dos pacientes o manifestaram durante o tratamento, tendo uma concentração maior para os doentes da forma $V(8)$ seguidos da $D(6)$.

A implantação da PQT provocou, segundo os profissionais, uma melhora da assiduidade dos pacientes e isso aparece claramente na análise da amostra, onde $97,4 \%$ são assíduos e apenas $2,6 \%$ são faltosos.

Nos pacientes em PQT do Estado de São Paulo, observou-se que a regularidade do comparecimento no serviço de saúde é de $92,5 \%$. Isto mostra que a tendência nò serviço de saúde local é a mesma do estado, segundo os dados obtidos junto ao centro de vigilância epidemiológica para o ano de 1991(16).

Tabela 3: Distribuição dos pacientes em PQT, segundo a presença ou não de tratamento anterior e o tempo de tratamento - São Carlos, 1992.

\begin{tabular}{c|c|c|c}
\hline \multirow{2}{*}{$\begin{array}{c}\text { Tempo de } \\
\text { Tratamento } \\
\text { (meses) }\end{array}$} & $\begin{array}{c}\text { Virgem } \\
\text { Tratamento }\end{array}$ & \multicolumn{2}{|c}{ Năo Virgem Tratamento } \\
\cline { 3 - 4 } & PQT & PQT & MONO \\
\hline$<6$ & $2(18,2 \%)$ & $2(7,4 \%)$ & - \\
\hline $6-12$ & $3(27,3 \%)$ & $20(74,0 \%)$ & - \\
\hline $12-24$ & $1(9,0 \%)$ & $5(18,6 \%)$ & - \\
\hline $24-27$ & $2(18,2 \%)$ & - & $1(3,7 \%)$ \\
\hline$>27$ & $3(27,3 \%)^{*}$ & - & $26(96,3 \%)$ \\
\hline TOTAL & $11(100 \%)$ & $27(100 \%)$ & $27(100 \%)$ \\
\hline
\end{tabular}

* Destes pacientes, 2 receberam alta e em virtude da demora do resultado dos exames, permaneceram inscritos no programa por mais tempo. O outro iniciou o tratmetno e o interrompeu, portanto teve que reiniciá-lo permanecendo mais tempo nos registros.

Com base nos dados da tabela 3 podemos concluir que, dos pacientes que eram virgens de tratamento, $45,5 \%$ estão na PQT no primeiro ano de tratamento, $9 \%$ estão entre o primeiro e o segundo ano de tratamento, $18,2 \%$ estão entre o $24^{\circ}$ e o $27^{\circ}$ mês e $27,3 \%$ estão com mais de 27 meses de tratamento. Dentre os pacientes que já fizeram terapias anteriores, foi verificado que a maioria permaneceu mais de dois anos sob a monoterapia, tendo inclusive pacientes com mais de 10 anos de tratamento. Daqueles que estiveram sob monoterapia e passaram para PQT, 7,4\% estão com menos de 6 meses de tratamento, $74 \%$ encontram-se entre $06^{\circ} \mathrm{e} 0$ $12^{\circ}$ mês, enquanto $18,6 \%$ estão entre o $1^{\circ} \mathrm{e} \circ 2^{\circ}$ ano de tratamento.

Tabela 4: Distribuição dos conceitos que o paciente tem sobre hanseníase - São Carlos, 1992.

\begin{tabular}{l|c|c}
\hline \multicolumn{1}{c|}{ Conceitos } & Número & $\%$ \\
\hline Problemas dermatológicos & 26 & 30,3 \\
\hline Problemas neurológicos & 22 & 25,6 \\
\hline Conceitos gerais & 22 & 25,6 \\
\hline Evoluçăo e prognóstico & 5 & 5,8 \\
\hline Informaços incorretas & 8 & 9,3 \\
\hline Năo sabe & 3 & 3,4 \\
\hline TOTAL & 86 & 100,0 \\
\hline
\end{tabular}

De acordo com a tabela $4,87,3 \%$ dos pacientes têm conceitos gerais e específicos sobre a doença, enquanto $12,7 \%$ não sabe ou têm informações incorretas sobre a mesma.

Tabela 5: Distribuição das respostas dos pacientes sobre os fatores relacionados à transmissão da doença - São Carlos, 1992

\begin{tabular}{l|c|c}
\hline \multicolumn{1}{c|}{ Transmissão } & Número & $\boldsymbol{\%}$ \\
\hline Contato pessoal com doentes & 14 & 30,4 \\
\hline Condiçoes de vida & 2 & 4,3 \\
\hline Conhecimento incorreto & 13 & 28,3 \\
\hline Năo sabe & 17 & 37,0 \\
\hline TOTAL & 46 & 100,0 \\
\hline
\end{tabular}


Na tabela 5 observa-se que $65,3 \%$ da amostra têm conhecimentos incorretos ou não sabem como se dá a transmissão da doença. Apenas $34,7 \%$ têm conhecimentos sobre este aspecto, pendurando portanto a idéia de transmissão vinculada ao contato pessoal com os doentes, mas sem entretanto ser especificado que tipo de contato.

Tabela 6: Distribuição das respostas dos pacientes sobre o tratamento em hanseniase São Carlos, 1992.

\begin{tabular}{l|c|c}
\hline \multicolumn{1}{c|}{ Conceitos } & Número & $\%$ \\
\hline Noçøes sobre PQT: & 18 & 26,9 \\
\hline $\begin{array}{l}\text { Conhece os medicamentos } \\
\text { utilizados }\end{array}$ & 10 & 15,0 \\
\hline O tratamento conduz à cura & 9 & 13,4 \\
\hline Otratamento inclui PI & 9 & 13,4 \\
\hline Exige restriçăo alcoólica & 7 & 10,4 \\
\hline Tempo de tratamento \\
(regularidade)
\end{tabular}

Conforme mostra a tabela $6,83,6 \%$ dos pacientes têm alguma noção sobre PQT, destacando-se que $26,9 \%$ dos entrevistados referiram conhecer a $s$ medicações utilizadas; por outro lado, $16,4 \%$ não sabem ou têm informações incorretas sobre o tratamento.

A credibilidade no tratamento segundo os dados apresentados é de $68,5 \%$, sendo que $31,5 \%$ não acreditam no mesmo devido a vários fatores, conforme os dados constantes da tabela 7. Entretanto, verifica-se que estes motivos são passiveis de solução na medida em que são desenvolvidas ações de educação em saúde visando um maior esclarecimento do paciente sobre essa questões relacionadas ao tratamento. em relação à confiabilidade $94,7 \%$ mostram que confiam no tratamento, enquanto que de acordo com a segurança $89,5 \%$ relatou que sente-se mais seguro com esse novo esquema terapêutico.
Tabela 7: Distribuição das respostas dos pacientes sobre a credibilidade do tratamento e sua justificativa - São Carlos, 1992.

\begin{tabular}{l|c|c|c}
\hline \multicolumn{1}{c|}{ Categorias } & Nåo & Sim & $\%$ \\
\hline Melhora de sintomatologia & 9 & - & 23,7 \\
\hline Avanço da medicina & 5 & - & 13,1 \\
\hline Faz o tratamento corretamente & 4 & - & 10,5 \\
\hline $\begin{array}{l}\text { Novos conhecimentos e experién- } \\
\text { cias de alta com terceiros }\end{array}$ & 4 & - & 10,5 \\
\hline Confiança nos médicos & 2 & - & 5,3 \\
\hline Fé em Deus & 2 & - & 5,3 \\
\hline Longo período de tratamento & - & 5 & 13,1 \\
\hline Incerteza & - & 5 & 13,1 \\
\hline Nấo aceita alta & - & 2 & 5,3 \\
\hline TOTAL & 26 & 12 & 100 \\
\hline
\end{tabular}

Tabela 8: Distribuição das respostas dos pacientes sobre a evolução do quadro clínico após o início do tratamento poliquimioterápico - São Carlos, 1992.

\begin{tabular}{l|c|c}
\hline \multicolumn{1}{c|}{ Categorias } & Número & $\%$ \\
\hline $\begin{array}{l}\text { Melhora da sintomatologia } \\
\text { neurologica }\end{array}$ & 10 & 35,0 \\
\hline $\begin{array}{l}\text { Melhora da sintomatologia } \\
\text { dermatológica }\end{array}$ & 17 & 29,9 \\
\hline Melhora do quadro geral & 4 & 7,0 \\
\hline Sem alteraçøes & 7 & 12,3 \\
\hline Outros & 9 & 15,8 \\
\hline TOTAL & 57 & 100,0 \\
\hline
\end{tabular}

Pode ser constatado através dos dados da tabela acima, que $71,92 \%$ dos pacientes manifestaram melhora do seu quadro clínico e 12,3\% referiram não ter tido qualquer alteração na sua sintomatologia.

Tabela 9: Distribuição das respostas dos pacientes quanto aos efeitos colaterais que apareceram após a administração da medicação específica - São Carlos, 1992.

\begin{tabular}{l|c|c}
\hline \multicolumn{1}{c|}{ Efeitos colaterais } & Número & $\%$ \\
\hline Alteraçøes gastrointestinais & 15 & 30,0 \\
\hline Alteraçøes dermatológicas & 7 & 14,0 \\
\hline Indisposiçåo & 6 & 12,0 \\
\hline Nenhum efeito & 9 & 18,0 \\
\hline Outros & 13 & 26,0 \\
\hline TOTAL & 50 & 100,0 \\
\hline
\end{tabular}


Através dos dados acima foi observado que $56 \%$ da amostra referiram ter tido efeitos colaterais, destacando-se as alterações gastrointestinais com $30,0 \%$ das respostas. Este é um dado negativo em relação ao tratamento, pois apesar de curar mais rapidamente, causa incômodos aos pacientes, conforme os dados.

Tabela 10: Distribuição das respostas dos pacientes quanto a dificuldade na realização do tratamento - São Carlos, 1992.

\begin{tabular}{l|c|c}
\hline \multicolumn{1}{c|}{ Categorias } & Número & $\%$ \\
\hline Problemas com o trabalho & 5 & 13,1 \\
\hline Transporte & 4 & 10,5 \\
\hline Problema financeiro & 4 & 10,5 \\
\hline Sem dificuldades & 21 & 55,3 \\
\hline Outros & 4 & 10,5 \\
\hline TOTAL & 38 & 100,0 \\
\hline
\end{tabular}

Das respostas obtidas, $10,5 \%$ dos pacientes não referem dificuldades na realização do tratamento, enquanto que $44,6 \%$ alegam dificuldades como :transporte, problemas financeiros e outros, havendo um equilíbrio entre as dificuldades referidas.

\subsection{Análise dos dados relacionados aos profissionais.}

A seguir, são apresentados os dados obtidos nas entrevistas realizadas com a equipe que atua junto ao programa de controle e eliminação da hanseniase. Para análise dos dados, as informações foram agrupadas, independentemente da categoria profissional.

Quanto à percepção dos profissionais frente a implantação da PQT, $\mathbf{8 8 , 4 \%}$ disseram que esta contribuiu para promover um melhor controle da doença, organização de serviço, integração entre o paciente e o serviço, e na assiduidade do paciente. Apenas $11,8 \%$ disseram que não ocorreram alterações na assiduidade do mesmo. Desse modo, os dados mostram que a maioria dos profissionais vêem a implantação deste esquema terapêutico como um aspecto bastante positivo para o controle e eliminação da hanseníase.
Tabela 11: Distribuição das respostas dos profissionais sobre a percepção para o controle frente a implantação da PQT - São Carlos, 1992.

\begin{tabular}{l|c|c}
\hline \multicolumn{1}{c|}{ Categorias } & Número & $\%$ \\
\hline Melhor controle da doença & 5 & 29,4 \\
\hline Melhor organizaçăo do serviço & 5 & 29,4 \\
\hline $\begin{array}{l}\text { Melhor assiduidade dos } \\
\text { pacientes }\end{array}$ & 4 & 23,5 \\
\hline Sem alteraçøes na assiduidade & 2 & 11,8 \\
\hline Melhor integraçăo paciente/S.S. & 1 & 5,9 \\
\hline TOTAL & 17 & 100,0 \\
\hline
\end{tabular}

Durante a implantação da PQT, as maiores dificuldades referidas pelos profissionais, relacionam-se à organização do serviço $(50,0 \%)$, destacando-se a falta de medicação especifica para o tratamento, a integração da equipe no desenvolvimento das suas ações, dificuldade na utilização de exames complementares (verificação da toxidade da RFM, estudo morfológico dos bacilos e outros) e ainda o comparecimento regular do paciente que trabalha.

A política de saúde vigente, dificultando o desenvolvimento eficaz e eficiente das ações de saúde, foi referida por um dos profissionais, e um outro aponta como obstáculo a dificuldade de absorção das informações fornecidas aos pacientes.

Tabela 12: Distribuição das respostas dos profissionais sobre as dificuldades durante a implantação da PQT - São Carlags, 1992.

\begin{tabular}{l|c|c}
\hline \multicolumn{1}{c|}{ Categorias } & Número & $\%$ \\
\hline Problemas organizacionais & 4 & 50,0 \\
\hline Política de saúde vigente & 1 & 12,5 \\
\hline $\begin{array}{l}\text { Paciente năo absorve as } \\
\text { orientaços }\end{array}$ & 1 & 12,5 \\
\hline Năo observou problemas & 2 & 25,0 \\
\hline TOTAL & 8 & 100,0 \\
\hline
\end{tabular}

Em relação à confiabilidade no tratamento, a maioria dos profissionais $(83,3 \%)$ refere confiança no mesmo, porém um deles afirma que não, devido à presença de pacientes que tiveram recidiva, necessitando portanto de se submeter a um novo esquema terapêutico.

Dos entrevistados, $66,6 \%$ acreditam na cura da doença em função dos resultados positivos e à eficiência dos medicamentos, enquanto $33,4 \%$ não acreditam devido aos resultados negativos (recaídas) e aos problemas da medicação (remédio não é o ideal). 
As demais questões do instrumento utilizado para a obtenção dos dados apontam que a administração da medicação supervisionada é realizada pela auxiliar de enfermagem que atua na área e foi devidamente treinada; na sua ausência esse procedimento é realizado pela enfermeira que está envolvida com as ações do programa, ou pela fisioterapeuta que atende aos pacientes de hanseníase.

O controle dos contatos é feito após a confirmação do diagnóstico do paciente, sendo o mesmo orientado quanto à importância do controle dos comunicantes, devendo estes comparecerem para consulta médica e receberem a primeira dose da vacina BCG; depois de um ano devem passar novamente por consulta médica, receber a segunda dose do BCG, as devidas orientações para que procurem o serviço quando observarem qualquer alteração e finalmente, a alta.

Caso seja necessário, é realizada uma visita domiciliar para comunicantes e pacientes, visando a orientação sobre a importância dos mesmos comparecerem ao serviço. A convocação destes se dá através do aerograma, sendo este um dos recursos que antecedem à visita domiciliar, quando da necessidade de comparecimento para consulta médica, administração de medicamentos ou vacinação.

Para inserir um paciente na $P Q T$, o médico usa de critérios como: história do paciente, exame clínico e laboratorial. Entretanto, existem alguns fatores que podem excluir o paciente desse esquema terapêutico como a diabetes, alcoolismo crônico, falta de disponibilidade para comparecer ao serviço mensalmente, etc. Se o paciente não tiver nenhum destes problemas, inicia imediatamente o tratamento poliquimioterápico.

Para dar alta, são usados critérios como: baciloscopia negativa para multibacilares; ausência de episódios reacionais; cura das lesões independentemente de seqüelas; ter completado as doses previstas no esquema e fazer uso correto da terapia instituída.

Durante o uso dos medicamentos da PQT foram observados em alguns pacientes, segundo os profissionais médicos da área, efeitos que poderiam estar relacionados com os medicamentos específicos comp: insuficiência renal pelo uso da RFM; estado pseudo-gripal (RFM); inapetência; obstipação intestinal; neuropatia periférica (DDS); ictiose e hiperpigmentação (CFZ).

Até o presente momento, desde a implantação da PQT, ocorreram duas recidivas de pacientes paucibacilares, os quais foram reintroduzidos no esquema correspondente. Também foi observado, que atualmente os pacientes recebem alta com um baixo grau ou nenhuma incapacidade.

\section{CONSIDERAÇÕES FINAIS}

Quando foram comparadas as normas técnicas e procedimentos estabelecidos a nivel central para a utilização dos esquemas de PQT no tratamento da hanseniase, com as ações que vem sendo desenvolvidas no ARE de São Carlos, podemos notar que os critérios adotados para a seleção dos casos introduzidos na PQT, condizem com o que tem sido preconizado pelo Ministério da Saúde. Apesar disso, há um número significativo de pacientes que ainda não foram inseridos no novo esquema em virtude desse processo estar em vias de implantação.

A administração das doses supervisionadas, assim como a aplicação do tratamento, são atribuições que cabem ao enfermeiro, diferentemente do que foi verificado no serviço.; no entanto, com base no treinamento prévio, os profissionais que desenvolvem esta atividade estão capacitados para tal, afastando a possibilidade de danos e/ou complicações que isso poderia trazer ao paciente.

Atualmente o controle dos contatos é realizado de acordo com os padrões preconizados, porém o reduzido número de comunicantes em controle se dá em virtude da carência de recursos destinados a este fim em épocas anteriores.

Para garantir a regularidade do paciente junto ao tratamento, são utilizados todos os recursos recomendados; aerograma, convocação por telefone, visitas domiciliares etc.

Os critérios preconizados para alta são adotados pelo serviço, porém para que sejam operacionalizados, freqüentemente são encontradas barreiras relacionadas a questões organizacionais, como por exemplo a realização do exame para índice morfológico que é feito em outra localidade, o que contribui pra uma permanência maior do paciente em registro ativo. 
A carência de recursos materiais, dentre os quais a insuficiência de medicamentos, dificulta a operacionalização das ações do programa. Um outro problema organizacional identificado, relaciona-se ao horário de atendimento do serviço, pois uma parcela significativa dos pacientes encontra dificuldade no comparecimento mensal devido ao horário de trabalho. Este fator acaba sendo um elemento importante, considerando-se os riscos que o paciente tem de perder o emprego e os problemas que advém associados ao estigma da doença.

A proposta de atuação de uma equipe multiprofissional junto ao programa, visa 0 atendimento integral do paciente e o cumprimento do mesmo na sua plenitude; entretanto, apesar dos profissionais serem integrantes do quadro de funcionários da unidade de saúde, verifica-se que não existe uma integração completa da equipe no sentido de concretizar o desenvolvimento da ações de foram efetiva e eficaz.

Frente a essa não participação ativa de to- dos os membros da equipe, devida inclusive a fatores alheios ao profissional, verifica-se que há um desestímulo junto aos mesmos que ali atuam, contribuindo de forma negativa na realização da atividades previstas, o que certamente interfere na qualidade da assistência prestada.

Acredita-se que uma medida passivel de intervenção seja a ativação da proposta, por parte da coordenação do $\mathrm{PCH}$ a nivel local, de atuação da equipe multiprofissional junto ao programa, visto que os profissionais estão presentes na unidade.

Um elemento primordial dessa intervenção seria a realização de um trabalho de sensibilização para educação em saúde com todos os profissionais do serviço, pois dessa forma, com as ações articuladas de uma equipe integrada, poder-se-ia chegar mais facilmente a propostas de mudanças de ordem organizacional, visto que estes problemas fazem parte de um sistema mais complexo e certamente refletem a trajetória da política de saúde vigente no país.

\section{REFERÊNCIAS BIBLIOGRÁFICAS}

1. BECHELLI, M.L. Alguns aspectos psicológicos, sociais e económicos relacionados com a lepra. Jomal Brasileiro Psiquiátrico. v.36, n.6, p.321-324, 1987.

2. BRASIL, Ministério da Saúde. Guia para o controle da hansenlase. 2. ed. Brasília. 1984.

3. Situaçăo de hanseniase no Brasil - 1987. Boletim Nacional de Epidemiologia. Ano I n.7. Brasilia, 1988.

4. Fundaçăo Nacional de Saúde - Dermatologia Sanitária - Centro Nacional de Epidemiologia. Legislaçáo sobre controle de doenças na área de dermatologia sanitária. Brasília, 192. 13p.

$5 . \quad$ Secretaria Nacional de Programas Especiais de Saúde - Divisáo Nacional de Dermatologia Sanitária. Normas técnicas e procedimentos para a utilização dos esquemas de poliquimioterapia no tratamento da hansenlase. 1988.

6. FRAGELLI, B. O vice da lepra - O Brasil é o único país onde a doença cresce. Isto é Senhor. 996:44. 19 de outubro de 1988.

7. HASSELBLAD, O. Lepra...uma interpretação atual. 4. ed. DNL-CERPLE, 1978, 22p.

8. LANA, F.C.F. Organização tecnológica do trabalho em hansenlase com a introduçăo da poliquimioterapia. Ribeirăo Preto, 1992. Dissertaçăo (Mestrado). Escola de Enfermagem de Ribeiråo Preto - USP, 1992.

9. LOMBARDI, C. Hanseniase: epidemiologia e controle. 1. ed. Sáo Paulo, Imprensa Ofícial do Estado S.A. IMESP. 1990.65p.
10. Situación epidemiologica de la lepra en 12 paises de América Latina $Y$ Caribe. Bol. of. Sanit. Panam. v.105, n.1, p.20-31, 1988.

11. MULTIDROGATERAPIA: Revoluçáo no tratamento da hanseniase. Pulso, v.26, n.594, 02 jun. 1986.

12. ORGANIZAÇĀO MUNDIAL DA SAÚDE. Série de Informes Técnicos. n.768, 1988. Comité de expertos de la OMS en lepra: sexto informe.

13. Leprosy suiveillance in the Americas. WKLY Epidem. Rec. v.59, n.22, p.165-168, 1984.

14. ORGANIZACIÓN PANAMERICANA DE LA SALUD. Situacion de los programas de control de la lepra en las Americas. Washington: Oficina Sanitária Panamericana. Oficina Regional de la Organizacion Mundial de la Salud. 1988.

15. PEDRAZZANI, E.S. A enfermagem de saúde pública no controle da hanseniase. Såo Paulo, 1984. Dissertaçăo (Mestrado) Faculdade de Saúde Pública - USP, 1984.

16. SÃO PAULO. Secretaria de Estado da Saúde - Centro de Vigiláncia epidemiológica - Divisáo Técnica de DSTI AIDS e Hanseníase. Dados epidemiológicos do Estado de Săo Paulo. 1991.

17. SOUZA, L.L. A poliquimioterapia e as açoes básicas de saúde. Jomal Morhan. jun, 1988.

18. TRABALHO de campo do Curso de Especializaça. Faculdade de Saúde Pública. s/d. (mimeografado).

Recebido para publicaçăo em 16.04 .94 